\title{
QUALITY AND PROSUMERSHIP. PROSERV: A NEW TOOL FOR MEASURING THE CUSTOMER SATISFACTION
}

\author{
Enrico Ciavolino* \\ University of Salento \\ Sergio Salvatore \\ University of Salento \\ Piergiorgio Mossi \\ University of Salento \\ Marta Vernai \\ University of Salento
}

\begin{abstract}
The current paper aims to present a new model for assessing the Customer Satisfaction. The model, named Prosumership Service Quality Model (PROSERV), can be seen as an extension of the European Customer Satisfaction Index (ECSI), where the centrality of the customer is developed in order to take into account the prosumership as a fundamental part of service quality and satisfaction. The theoretical model has been formalized in 4 hypotheses: (HP1) the PROSERV-Q questionnaire has a good level of reliability; (HP2) the PROSERV-Q underlies the three level abstraction modelled by PROSERV; the estimated level of overall satisfaction has high correlation with the external global satisfaction index (HP3) and Loyalty (HP4). In order to test these hypotheses, the PROSERV - and the associated questionnaire PROSERV-Q - are applied to a sample of 680 customers of services. The theoretical model has been conceptualized as a three levels hierarchical structure, and statistically formalized with the PLS Path Modelling (PLS-PM) with higher-order constructs. Results are consistent with hypotheses, in that providing evidence that the three-level PROSERV model is able to capture the fundamental constitutive components of customer satisfaction and, at same time, affects the loyalty.
\end{abstract}

Keywords: Customer Satisfaction; Service; Prosumership; PROMSERV.

\section{INTRODUCTION}

Customer satisfaction is broadly considered one of the most relevant indicators for the company's success (Matzler et al., 1996) as well as a key point of service quality (Oliver, 2010).

The shift of perspective introduced by the Total Quality philosophy lead to recognize the relevance of service quality (Deming, 1986; Neave, 1987). Such a perspective introduced the client as the main parameter for the determination of the value of the service, therefore the fundamental criterion of marketing strategies (Mehra \& Ranganathan, 2008) - the producer's aim is not limited to delivering output with the expected quality characteristics, but is to satisfy the client.

* Department of History, Society and Human Studies. University of Salento. Studium 2000, Edificio 5, Stanza 39, Via di Valesio, 73100, LECCE (Italy). e-mail: enrico.ciavolino@unisalento.it 
Thus, such a shift has led to the recognition of the strategic relevance of customer satisfaction. As a result, a stream of efforts aimed at mapping and measuring the client's perception of service quality and satisfaction has been developed over the last two decades.

SERVQUAL may be the first tool to achieve worldwide recognition among proposals aimed at modelling and measuring customer satisfaction (Parasuraman et al., 1988). This model focuses on the gap between expected and perceived quality, concerning five main dimensions: reliability, responsiveness, assurance, empathy and tangibles. The model is grounded on the assumption that the satisfaction is due to the coherence between the former and the latter (Parasuraman et al., 1985).

The SERVQUAL model had great success; yet it raised various criticisms as to the theoretical assumption it is grounded on (in particular, the differential conception of satisfaction) and the computational approach adopted (Ladhari, 2009). In particular, Cronin e Taylor (Cronin Jr and Taylor, 1994) challenged the Parasuraman, Zeithaml and Berry $(1985,1988)$ framework, and proposed a performance-based measure of service quality (SERVPERF). According to SERVPERF, service quality concerns the perception of the service performance in itself, rather than the difference between the latter and the expected quality.

A further development in the field has been provided by the introduction of the issue of causal linkages between perception of quality and satisfaction as well as different components of the relationship between client and provider (e.g. loyalty). More particularly, several instruments have been developed with country-level focus - ACSI (American Customer Satisfaction Index, Anderson \& Fornell, 2000), NCSB (Norwegian Customer Satisfaction Andreassen \& Lindestad, 1988); SCSB (Swedish Customer Satisfaction, Fornell, 1992).

The latter instruments underwent a further development, becoming a tool to be used at European level: (ECSI; European Customer Satisfaction Index). In the last 30 years ECSI has been gaining a leading position within the field - nowadays it represents one of the most used-if not the foremost - reference point in the measurement of customer satisfaction in the European milieu (Bayol et al., 2000; Gronholdt et al., 2000; Kristensen et al., 2000).

The ECSI model is based on the set of exogenous latent variables (Image, Expectation, Hardware, Software) and endogenous variables (Perceived Value, Customer Satisfaction, Loyalty) that can be graphically represented by a path diagram, as shown in Figure 1.

ECSI was developed in the framework of the centrality of the client. Accordingly, both the endogenous and exogenous parameters are focused on the experience the client has of the product/service and the attitude and commitment resulting from such experience. On the other hand, the concept of the centrality of the client has undergone significant development over the last two decades, moving in a direction that was not in the foreground when the ECSI model was elaborated. Indeed, the increasing priority of services over products (Norman, 1986) has led to a re-interpretation of the notion of the centrality of the client in relational dynamics - namely in terms of prosumership (Norman, 1986; Grönroos, 2000; Mossi \& Salvatore, 2012).

The tenet of the prosumership does not rule out the notion of the centrality of the client. Rather, it develops it further, in the sense of considering the client-service relation not only as a source and/or a result of the client's experience of the service, but as a constitutive component of the service's construction and delivery. According to such a perspective, the client is not the mere user of the service, 
Figure 1: The ECSI Model

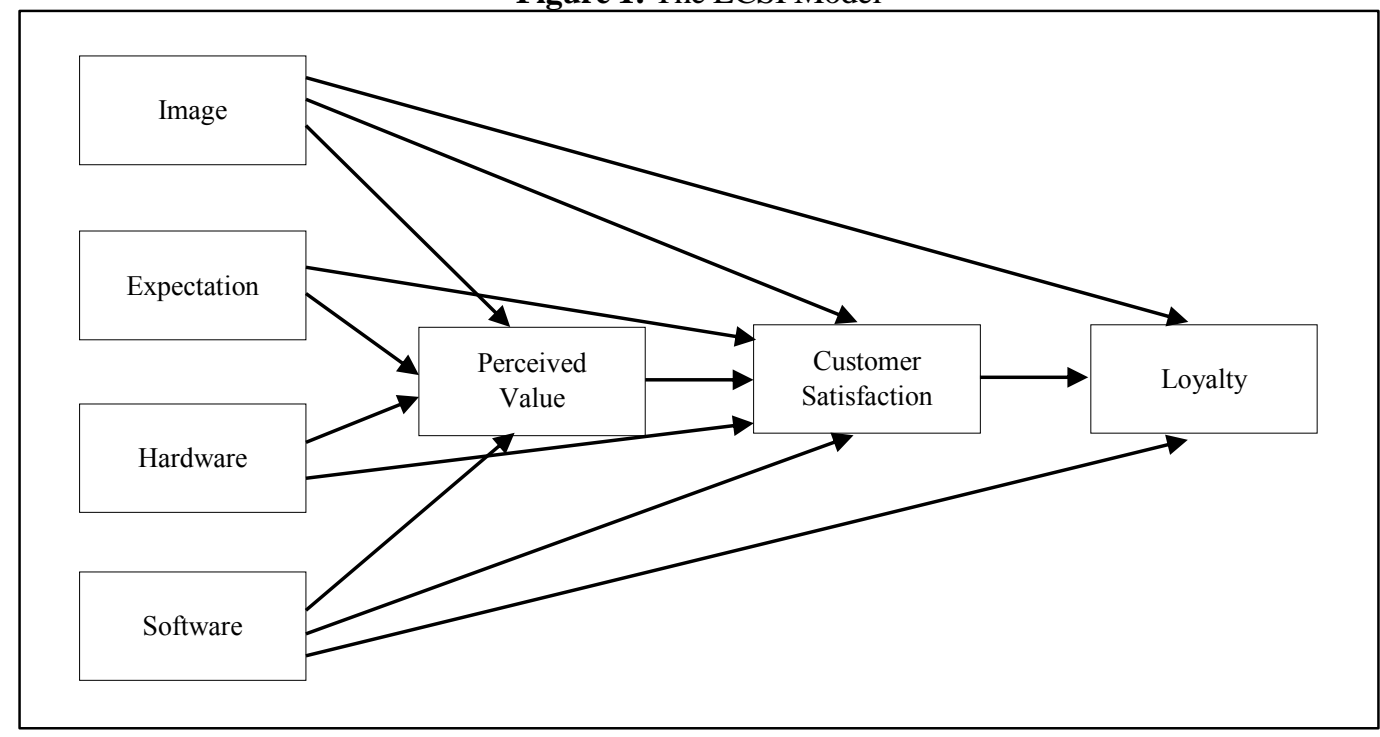

but both its producer and its consumer - its pro-sumer (Norman, 1986). This is as a result of the immateriality of the service; due to this characteristic, the service - even when it is mediated by material components - is generated necessarily within and through the dynamic relation between the client and the provider, as a function of the client's active participation in the relationship. For instance, the bank service cannot be reduced to a matter of the type of services supplied by the provider (e.g. a trust bank account), given that it is the client that generates the functionality of such services through the way he/she uses them. Again, at a more concrete level, take home banking that enables clients to manage their position within the bank's functional environment, carrying out tasks that would otherwise be the bank's responsibility. In so doing, the client assumes the role of a provider's production factor (Norman, 1986; Zeithaml \& Bitner 2003, Salvatore et al, 2017).

The tenet of prosumership makes the relation with the client a key point of the provider's success, given that the very construction of the service depends on the dynamic, co-constructive integration of the client within the boundaries of the productive process of the service. Accordingly, the client-provider prosumership relationship needs to be taken into account not only as the result of the experience of the service, but as one of the components of service construction, to be measured and mapped. Hence the recognition of the need to update the current approaches to the measurement of customer satisfaction, limited to the relational dimension (i.e. Loyalty in the ECSI), but seen as a result of satisfaction, rather than a constitutive component of it.

The current study intends to contribute to this line of work, by presenting a new model - and associated measurement tool - of customer satisfaction, Prosumership Service Quality Model (PROSERV), inspired by the ECSI's view of the centrality of the client, yet developing such a view in order to take prosumership into account as a fundamental component of service quality and satisfaction. In the following sections, the PROMSERV model is presented and the findings of a initial validation study are reported. 


\section{PROSERV}

\subsection{The PROSERV model of satisfaction}

Figure 2 outlines the PROSERV model of satisfaction.

Figure 2: The PROSERV model

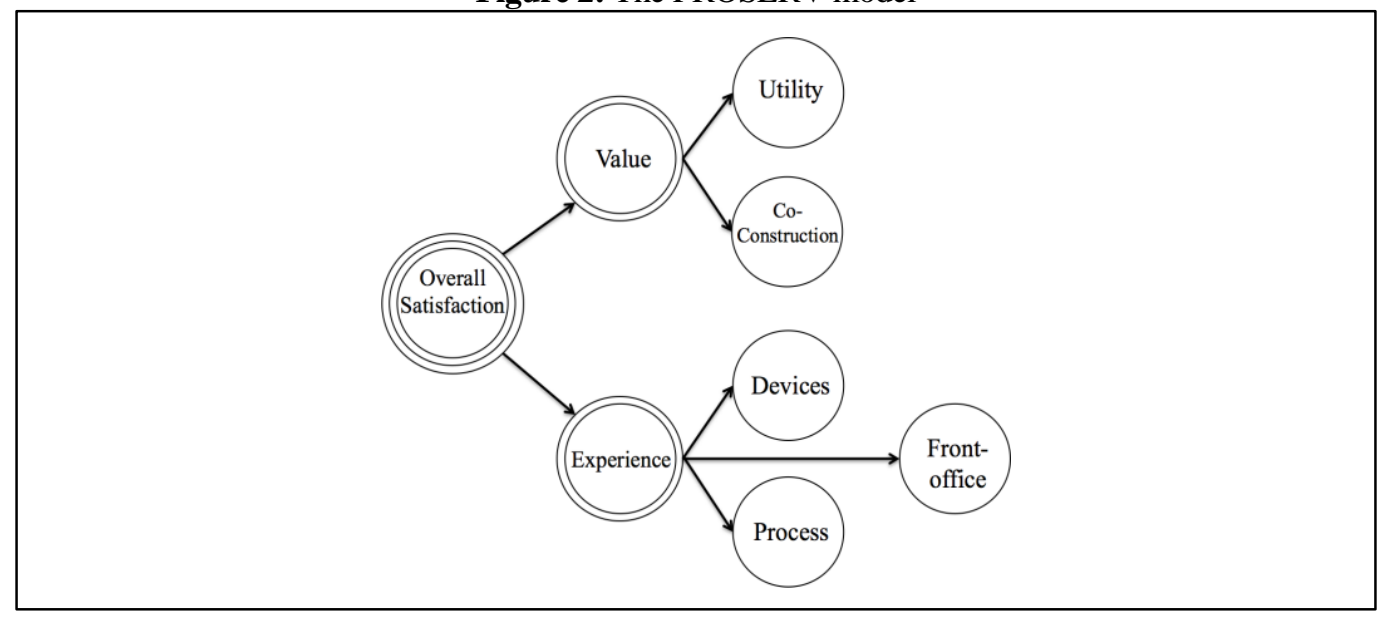

The model is based on the fundamental distinction between two areas of meaning that are expected both to be involved in any form of value construction: the affective-laden, situated subjective experience of the relational events through which the service is performed (in PROSERV terminology: EXPERIENCE) and the significance the client attributes to the outcome of the transaction with the provider in terms of his/her own project (VALUE). This distinction is significant and derives from the interpretation of the provider-client transaction in terms of service (Norman, 1986; Grönroos, 2000; Salvatore et al, 2017). Indeed, according to such an interpretation, the provider-client transaction is an inherent relational event; consequently, the client-provider relationship is not only the container of the functional transaction, but a constitutive part of the transaction, one of the main components through which the transaction generates value. Incidentally, this view is consistent with a great deal of psychological literature that has highlighted how the value of the output of a certain system of activity is contingent to the contextual, situated meaning negotiated within that system. For instance, the output of an educational activity depends on how it is interpreted by the actors involved in it (e.g. Venuleo, Mossi, Salvatore, 2016; Salvatore, Ligorio \& De Franchis, 2005); again, the effectiveness of treatments (be it psychological or medical) is greatly affected by the quality of the relation between provider and patient (Tanzilli, Colli, Del Corno \& Lingiardi, 2016; Salvatore \& Gennaro, 2012; Rocco et al. 2017).

PROSERV identifies components for both VALUE and EXPERIENCE and in so doing is defined as a three level model.

\subsubsection{VALUE}

VALUE concerns client's interpretation of the outcome of the transaction with the provider. This dimension is divided into two components: UTILITY and CO-CONSTRUCTION 
i. UTILITY clusters facets concerning the evaluation of the transaction's capacity to satisfy the client's demand, namely its capacity to work for the sake of the client's project. This dimension derives from the tenet of prosumership and from the recognition of the immateriality of the service. Indeed, according to these two complementary views, the client is an active subject involved in the construction of value, participating both to its production and interpretation. Consequently, the client has to be considered not only or mainly as the passive conveyer of a need to be fulfilled, but as the conveyer of a project/purpose for which the provider is a resource (Mossi \& Salvatore, 2012; Salvatore \& Scotto di Carlo, 2005). Accordingly, satisfaction does not consist of the inner quality of the output, but of its utility for the client.

ii. CO-CONSTRUCTION clusters facets that concern the client's perception of the service as a transaction that adjusts its purposes in order to fit the client's purpose, thus qualifying as a dynamic of coconstruction. We consider this as the main marker of Prosumership: the view of service as a transitional, liminal dynamics (Salvatore \& Venuleo, 2017; Salvatore et al, 2017), where the client works for the sake of the production process insofar as this process is able to act as a client's resource. On the other hand, it is worth noting that even if the co-construction inherently concerns the relationship between client and provider, PROSERV considers it part of the VALUE, rather than EXPERIENCE. This is so because co-construction goes beyond the situated experience of service - it represents the source of the symbolic value attributed to the position of the client - i.e. a client that perceives the efforts of the provider to adapt to his purpose receives from the service an image of her/himself as a valuable person. Therefore, PROSERV regards co-construction as the service's level of identity and symbolic value.

\subsubsection{EXPERIENCE}

EXPERIENCE concerns facets characterizing the situated, subjective lived state the client associates with the relational exchange with the provider. PROSERV clusters these facets into three components PROCESS, FRONT-OFFICE and DEVICES:

i. PROCESS concerns characteristics of the procedures/actions involved in the transaction between provider and user - e.g. accessibility and flexibility. This component is similar to the ECSI dimension "Software"- what distinguishes it from the latter is the main focus on the aspects of service that may have an impact on the client's subjective experience of the service and of oneself as a client of it - e.g. Uniformity of customer treatment; Transparency decisions.

ii. FRONT-OFFICE concerns the qualities of the personnel that are the user's points of contact with the provider, namely what the client experiences of the service - e.g., organizational skills and reliability. The decision to consider a specific cluster for this kind of facets, distinguishing it from Process is consistent with the recognition of the immateriality of the service. It follows that the experience of the service is expected to be strongly affected by the human relationship mediating it. Norman (1986) defines services as "personality intensive enterprises"

iii. DEVICES concerns the qualities and characteristics of the material and structural facets of the service. Also this component is similar to an ECSI dimension: "Hardware". The facets of this cluster were chosen because they are expected to have an impact on the client's subjective experience (e.g. the Aesthetic Environment, Security Level), not because of their objective functional relevance. 
Before concluding, it is worth noting a further significant difference between PROSERV and ECSI unlike the latter, PROSERV does not encompass Loyalty. This is because PROSERV considers Loyalty a behavioural consequence of customer satisfaction, rather than an inherent part of it. Needless to say, Loyalty is not only a behaviour, but also an act of meaning (Mossi \& Salvatore, 2012): the client that claims her/his loyalty to a certain provider is not only foreseeing that in the near future he will continue the relationship with that provider, but is also enacting an image of her/himself (i.e. "I am a satisfied client") as well as a representation of the provider ("it is a worthy provider"). On the other hand, these two aspects of Loyalty (i.e. behavioural and symbolic), though connected, are worth distinguishing. Indeed, one can claim loyalty for its symbolic valence, even if no behavioural choice derives from such a statement; and vice versa, one can be loyal at a behavioural level, without attributing symbolic meaning to such a behavioural choice (i.e. just out of habit). In the case of PROSERV, the symbolic valence of Loyalty is already considered, being implicitly entailed by the component CoCONSTRUCTION; the behavioural component of Loyalty is viewed as an outcome of customer satisfaction and as such it is not included in the model, but considered an external aspect that customer satisfaction has to predict.

\subsection{PROSERV-Q}

PROSERV-Q is a 22-item questionnaire designed to estimate the level of customer satisfaction, as modelled by PROSERV.

Items have been defined in order to map the five PROSERV components (UTILITY, CO-CONSTRUCTION, DEVICES, FRONT-OFFICE, PROCESS). Table 1 shows the items used for detecting the corresponding components.

Table 1: PROSERV components and corresponding items

\begin{tabular}{|c|c|c|}
\hline LVs & $\begin{array}{r}\text { MVs } \\
\end{array}$ & Label* \\
\hline \multirow{3}{*}{ UTILITY } & Value in terms of costs / benefits & $\mathrm{Ut}_{1}$ \\
\hline & Service utility & $\mathrm{Ut}_{2}$ \\
\hline & Ability to fulfil requests & $\mathrm{Ut}_{3}$ \\
\hline \multirow{6}{*}{ CO-CONSTRUCTION } & Taking needs / constraints into account & $\mathrm{Co}_{1}$ \\
\hline & Finding customised solutions & $\mathrm{CO}_{2}$ \\
\hline & Being involved in defining the service & $\mathrm{Co}_{3}$ \\
\hline & Willingness to make changes to meet requests & $\mathrm{Co}_{4}$ \\
\hline & Being Considered & $\operatorname{Co} 5$ \\
\hline & Creating links & $\mathrm{Co}_{6}$ \\
\hline \multirow{3}{*}{ DEVICES } & Comfort Environments & $\mathrm{De}_{1}$ \\
\hline & Aesthetic Environments & $\mathrm{De}_{2}$ \\
\hline & Security Level & $\mathrm{De}_{3}$ \\
\hline \multirow{4}{*}{ FRONT-OFFICE } & Technical Expertise & $\mathrm{Fr}_{1}$ \\
\hline & Organization Skills & $\mathrm{Fr}_{2}$ \\
\hline & Reliability & $\mathrm{Fr}_{3}$ \\
\hline & Courtesy & $\mathrm{Fr}_{4}$ \\
\hline \multirow{6}{*}{ PROCESS } & Uniformity of customer treatment & $\operatorname{Pr}_{1}$ \\
\hline & Accessibility & $\operatorname{Pr}_{2}$ \\
\hline & Flexibility & $\operatorname{Pr} 3$ \\
\hline & Correspondence Methods Expected/Adopted & $\operatorname{Pr}_{4}$ \\
\hline & Transparent decisions & $\operatorname{Pr}_{5}$ \\
\hline & Waiting time & Pr6 \\
\hline
\end{tabular}


As can be seen, items vary as to the level of specificity - some items refer to specific components of service (e.g. the aesthetic quality of the environments) other items refer to larger, global aspects (e.g. accessibility, uniformity of treatment). Therefore, two item formats are used:

Items concerning specific characteristics/components - e.g. Aesthetic Environments, Security Level, Technical Expertise, Waiting time, - consist of a 5-point Likert bidirectional scale of satisfaction ("Very dissatisfied", "Partially dissatisfied", "Neither satisfied nor dissatisfied", "Partially satisfied", "Very satisfied").

Items concerning more global characteristics - e.g. Being involved in defining the service, Willingness to make changes to fulfil requests, being considered-consist of statements associated with a 5-point Likert bidirectional scale of (dis)agreement.

The use of a bidirectional scales is aimed at allowing the client to express disaffection/disagreement (rather than lack of satisfaction/agreement). Indeed, this possibility is considered an important factor in promoting the relationship between the provider and users, because it entails the view of the provider as willing to accept the autonomy of the client, namely the possibility that the client may have a negative attitude towards the providers (Mossi \& Salvatore, 2012; for a discussion on the psychological view that shows how the quality of the relationship is empowered by the capacity to welcome and manage the conflictual, negative aspects, rather than avoiding them, see Safran \& Muran, 2000).

The questionnaire includes a set of additional items aimed at describing the socio-demographic characteristics of respondents (i.e. gender, age, qualification, occupation) as well as their position with respect to the service (e.g. intensive user).

In the current version, the questionnaire is applied in paper and pencil mode. However, it is easily adaptable to an on-line mode.

\section{AIM AND HYPOTHESIS}

The following sections of the paper report the case study performed in order to subject PROSERV to an initial test of reliability and validity.

More particularly, the study tested the following hypotheses:

a) PROSERV-Q is characterized by a good level of reliability (HP1).

b) PROSERV-Q underlies the 3-level model of satisfaction outlined by the PROSERV model (HP2).

c) PROSERV-Q third level dimension "OVERALL SATISFACTION"correlates with an independent, direct measure of global satisfaction (HP3).

d) PROSERV-Q third level dimension “OVERALl SATISFACTION"affects the level of Loyalty (HP4).

As one can see, HP1 concerns the reliability of the tool; HP2 and HP3 concern the construct validity; HP4 concerns the criterion validity. 


\section{METHOD}

In order to test the hypotheses about PROSERV's reliability and construct validity a Partial Least Squares Path Modeling (PLS-PM) was performed with the aim of analysing the content and the intra and inter-level relations between the dimensions.

\subsection{Sample}

The study was based on a convenience non-proportional sample composed of 680 users of services $53.9 \%$ women; age: $\mathrm{M}=40.77$; $\mathrm{sd}=13,270$ - recruited in 5 sectors: hotels, banks, post offices, restaurants and medical offices. The decision to use a plurality of contexts was made with the aim of expanding the coverage of the potential sources of variability, according to the criterion of maximum variability (Blalock Jr, 1960, Salvatore, 2016). All respondents were recruited in Apulia (a Southern Italian Region).

Table 2 shows the distribution of the sample over the 5 sectors.

Table 2: Sample*service sectors

\begin{tabular}{ccc}
\hline \hline Sectors & Frequency & \% \\
\hline Hotels & 136 & 20 \\
Bank & 139 & 20,4 \\
Post Office & 137 & 20,1 \\
Restaurant & 137 & 20,1 \\
Medical centers & 131 & 19,3 \\
Total & 680 & 100 \\
\hline \hline
\end{tabular}

\subsection{Indicators}

An independent, self-report measure of Global Satisfaction was based on the following three items (we adopted a 3 -item indicator in order to increase the reliability of the measurement):

i. Taken as a whole, how satisfied are you with the service?

ii. Taken as a whole, how does the service fulfil your expectation?

iii. Taken as a whole, how satisfied are you with the quality of the service?

The 3 items are to be answered on a 5-point Likert scale - from "Very unsatisfied" to "Very satisfied"). The three items underwent factorial analysis (Principal Component Analysis). The first factor (92\% explained variance; all 3 coefficient loadings higher than 0.95 ) was used as the indicator of Global satisfaction.

As the indicator of Loyalty we adopted the following item: "The service will keep me as a client in the future". The item was to be answered on a 5-point Likert scale - from "Fully disagree" to "Fully agree").

\subsection{Partial Least Squares Path Modelling (PLS-PM)}

In order to explore the structure of the collected data and to test the hypothesized model, a procedure of analysis based on PLS Path Modelling(PLS-PM) with high order constructs was implemented. 
The PLS-PM was chosen since it is a suitable method to define and analyse latent variables models with a higher degree of abstraction (Ciavolino, 2013). Moreover, the Partial Least Squares estimator is very flexible and robust; it requires no distributional assumption and fewer requirements for the identification of the model (Ciavolino, 2013; Lohmöller, 1989; Nitti \& Ciavolino, 2014).

The approach used in this paper to analyse the three hierarchical levels is the Hierarchical Component Model or Repeated Indicators Approach (RIA, Lohmöller, 1989), where the manifest indicators of each first-order LV, are simply repeated at each level of hierarchy, in order to represent the higher-order constructs.

Consistently with the PROSERV model (cf.Figure 1), the following three types of LVs were defined:

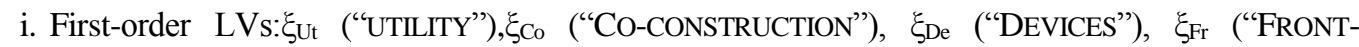
OFFICE"), $\xi_{\text {Pr }}$ ("PROCESS"). The first-order LVs were regarded as independent. This assumption of independence was made because, according to PROSERV, these constructs concern separate objects with no great semantic linkage between them. Consequently, in the first-order model, no causative relationships among the constructs were assumed, which limited the analysis to a descriptive calculation of the correlation (Pearson's coefficient) between them.

ii. Second-order LVs: ( $\xi^{\mathrm{II}} \mathrm{Va}$ e $\xi_{\mathrm{Ex}}^{\mathrm{II}}$ ). The second-order LVs refers to the 2 PROSERV dimensions:VALUE and EXPERIENCE; According to PROSERV, each dimension is assumed to underlie some first order LVs (cf. Figures 1 and 2).

iii. Third-order construct ( $\xi^{\mathrm{III}} \mathrm{Ov}$ ), named "OVERALL SATISFACTION", is assumed to underlie the two second-order LVs (cf. Figures 1 and 2).

Figure 3 also outlines the measurement (outer) model; the details of the 22 Manifest Variables are reported in Table 1.

Figure 3: Inner and outer model

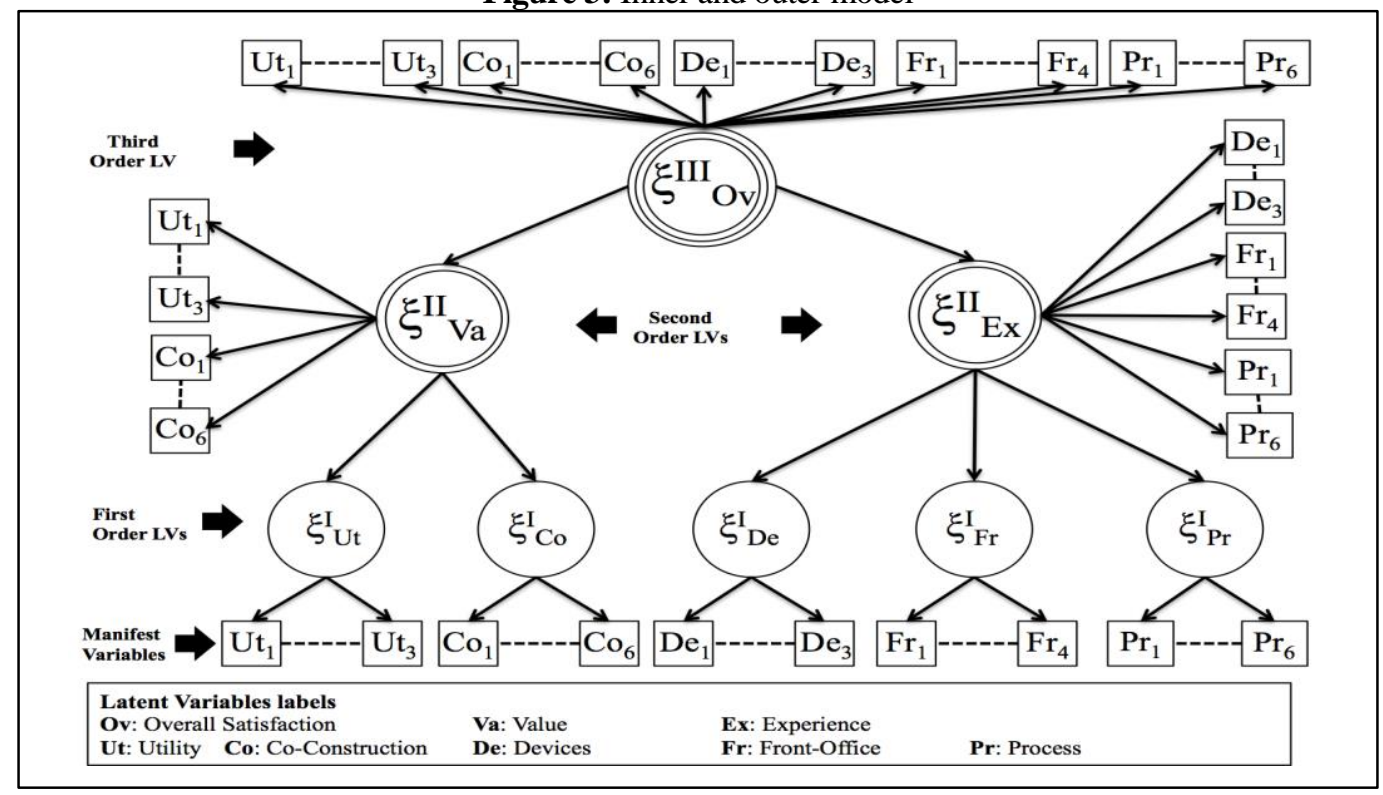




\section{RESULTS}

In the following sections the main results of the PLS-PM are reported as well as further analyses concerning Overall Satisfaction. The first section refers to the validation of the measurement model; the second one concerns the structural model between the higher-order LVs. The third section reports the output of the further analyses.

\subsection{Scale evaluation}

Table 3 shows the composite reliability - DG-rho and Cronbach's $\alpha$ index - assessing the quality of the measurement model.

Table 3: DG-rho and Cronbach's $\alpha$ indexes

\begin{tabular}{ccccccc}
\hline \hline & Mode & MVs & C.alpha & DG.rho & Eig.1st & Eig.2nd \\
\hline OVERALL & $\mathrm{A}$ & 22 & 0.97 & 0.97 & 12.90 & 1.46 \\
VALUE & $\mathrm{A}$ & 19 & 0.95 & 0.96 & 6.40 & 0.82 \\
EXPERIENCE & $\mathrm{A}$ & 13 & 0.94 & 0.94 & 7.43 & 1.43 \\
UTILITY & $\mathrm{A}$ & 3 & 0.91 & 0.94 & 2.55 & 0.27 \\
CO-CONSTRUCTION & $\mathrm{A}$ & 5 & 0.93 & 0.95 & 3.94 & 0.39 \\
DEVICES & $\mathrm{A}$ & 3 & 0.84 & 0.91 & 2.29 & 0.50 \\
FRONT-OFFICE & $\mathrm{A}$ & 4 & 0.93 & 0.95 & 3.34 & 0.32 \\
PROCESS & $\mathrm{A}$ & 6 & 0.91 & 0.93 & 4.10 & 0.54 \\
\hline \hline
\end{tabular}

All Cronbach's $\alpha$ indexes are above the conventional acceptability of 0.7 , all LVs being close to 0.9 $(0.97,0.95,0.94,0.91,0.93,0.84,0.93,0.91)$; Composite reliability $(\mathrm{CR})$ is higher than 0.7 for all constructs. Also the communality index appears high for all manifest constructs. These blocks are therefore considered homogenous and unidimensional.

The analysis of the eigenvalues confirms the unidimensionality of the LVs. Indeed, only the first eigenvalue for each LVis greater than one. Moreover, the scree test applied to the comparison of the first and second eigenvalues (Table 4, last two columns) supports the block's one-dimensionality. Indeed in all cases, there is a big gap between the first and second eigenvalue (e.g. for Overall Satisfaction from 12.90 to 1.46 ).

Convergent validity is assessed through cross-loadings analysis. Cross-loadings are the loadings of an indicator with the rest of latent variables - accordingly, cross loadings analysis can be assimilated to a procedure of Principal Component Analysis.

By means of the cross loading analysis, one can check if the model is consistent with the important assumption that the manifest variables and the latent variables must be related; more particularly, each manifest variable must have a positive correlation with its latent variable which must be higher than with any other latent variable.

Table 4 presents the output of the cross loadings analysis applied on the dataset. The coloured values indicate the manifest variables (in rows) that characterize the latent variables (columns 4-10). Therefore, variables $\operatorname{Pr}_{1}, \operatorname{Pr}_{2}, \operatorname{Pr}_{3}, \operatorname{Pr}_{4}, \operatorname{Pr}_{5}$ define the component called "PROCESS", while variables $\mathrm{Fr}_{1}, \mathrm{Fr}_{2}, \mathrm{Fr}_{3}, \mathrm{Fr}_{4}$ define the component called "FrONT-OFFICE", variables De $_{1}, \mathrm{De}_{2}$, De $_{3}$ define the variable "DEVICES". 
As one can see, for each manifest variable, the loading is higher for its reflective latent variables than for other latent variables. For example, manifest variables $\mathrm{Ut}_{1}, \mathrm{Ut}_{2}, \mathrm{Ut}_{3}$, assumed to have UTILITY (Ut) as reflective latent variable, have loadings for this latent variable $(0.904,0.934,0.927)$ which are higher than the loadings for the other first-order latent variables. In the same way, manifest variables $-\mathrm{Co}_{1}, \mathrm{Co}_{2}$, $\mathrm{Co}_{3}, \mathrm{Co}_{4}, \mathrm{Co}_{5}$, and $\mathrm{Co}_{6}$ - have higher loadings $(0.810,0.868,0.867,0.917,0.912,0.875)$ for their assumed reflective latent variable - CO-CONSTRUCTION $(\mathrm{Co})$ - than the other loading for the other first-order latent variables.

Table 4: Cross-Loadings

\begin{tabular}{|c|c|c|c|c|c|c|c|c|c|}
\hline $2^{\text {nd }} L V$ & $\mathbf{1}^{\mathrm{rd}} \mathbf{L V}$ & MVs & VAlue & EXPERIENCE & UTILITY & $\begin{array}{c}\text { Co- } \\
\text { CONSTRUCT }\end{array}$ & DEVICES & $\begin{array}{l}\text { FrONT- } \\
\text { OFFICE }\end{array}$ & Process \\
\hline VALUE & $U T$ & $\mathrm{Ut}_{1}$ & 0.818 & 0.753 & 0.904 & 0.688 & 0.486 & 0.691 & 0.714 \\
\hline VALUE & $U T$ & $\mathrm{Ut}_{2}$ & 0.811 & 0.747 & 0.934 & 0.664 & 0.473 & 0.682 & 0.716 \\
\hline VALUE & $U T$ & $\mathrm{Ut}_{3}$ & 0.836 & 0.770 & 0.927 & 0.700 & 0.446 & 0.738 & 0.729 \\
\hline VALUE & $\mathrm{Co}$ & $\mathrm{Co}_{1}$ & 0.853 & 0.734 & 0.681 & 0.810 & 0.499 & 0.664 & 0.691 \\
\hline VALUE & $\mathrm{CO}$ & $\mathrm{CO}_{2}$ & 0.857 & 0.706 & 0.674 & 0.868 & 0.448 & 0.631 & 0.687 \\
\hline VALUE & $\mathrm{CO}$ & $\mathrm{Co}_{3}$ & 0.811 & 0.651 & 0.600 & 0.867 & 0.438 & 0.579 & 0.625 \\
\hline VALUE & $\mathrm{CO}$ & $\mathrm{Co}_{4}$ & 0.877 & 0.716 & 0.671 & 0.917 & 0.464 & 0.648 & 0.685 \\
\hline VALUE & $\mathrm{CO}$ & $\mathrm{Co} 5$ & 0.885 & 0.765 & 0.698 & 0.912 & 0.488 & 0.693 & 0.735 \\
\hline VALUE & $\mathrm{Co}$ & $\mathrm{Co}_{6}$ & 0.835 & 0.710 & 0.648 & 0.875 & 0.486 & 0.641 & 0.669 \\
\hline EXPERIENCE & $D E V$ & $\mathrm{De}_{1}$ & 0.496 & 0.621 & 0.456 & 0.463 & 0.897 & 0.437 & 0.465 \\
\hline EXPERIENCE & $D E V$ & $\mathrm{De}_{2}$ & 0.505 & 0.636 & 0.467 & 0.472 & 0.913 & 0.449 & 0.478 \\
\hline EXPERIENCE & DEV & $\mathrm{De}_{3}$ & 0.458 & 0.572 & 0.404 & 0.436 & 0.805 & 0.387 & 0.451 \\
\hline EXPERIENCE & $F_{R}$ & $\mathrm{Fr}_{1}$ & 0.695 & 0.806 & 0.698 & 0.622 & 0.466 & 0.899 & 0.664 \\
\hline EXPERIENCE & $F R$ & $\mathrm{Fr}_{2}$ & 0.735 & 0.844 & 0.724 & 0.668 & 0.451 & 0.940 & 0.712 \\
\hline EXPERIENCE & $F R$ & $\mathrm{Fr}_{3}$ & 0.731 & 0.841 & 0.706 & 0.668 & 0.461 & 0.930 & 0.711 \\
\hline EXPERIENCE & $F R$ & $\mathrm{Fr}_{4}$ & 0.718 & 0.802 & 0.661 & 0.674 & 0.402 & 0.886 & 0.696 \\
\hline EXPERIENCE & $P R$ & $\operatorname{Pr}_{1}$ & 0.681 & 0.762 & 0.640 & 0.638 & 0.420 & 0.659 & 0.789 \\
\hline EXPERIENCE & $P R$ & $\operatorname{Pr}_{2}$ & 0.602 & 0.748 & 0.593 & 0.542 & 0.441 & 0.585 & 0.812 \\
\hline EXPERIENCE & $P R$ & $\operatorname{Pr}_{3}$ & 0.730 & 0.831 & 0.686 & 0.679 & 0.456 & 0.688 & 0.884 \\
\hline EXPERIENCE & $P R$ & $\operatorname{Pr}_{4}$ & 0.744 & 0.809 & 0.697 & 0.693 & 0.486 & 0.634 & 0.869 \\
\hline EXPERIENCE & $P R$ & $\operatorname{Pr}_{5}$ & 0.723 & 0.785 & 0.683 & 0.674 & 0.441 & 0.637 & 0.842 \\
\hline EXPERIENCE & $P R$ & $\operatorname{Pr}_{6}$ & 0.600 & 0.701 & 0.561 & 0.566 & 0.393 & 0.566 & 0.754 \\
\hline
\end{tabular}

The second-order variable, "VALUE", is more defined by all manifest variables that characterize "UTILITY" and "CO-CONSTRUCTION" variables, in particular $\mathrm{Ut}_{1}, \mathrm{Ut}_{2}, \mathrm{Ut}_{3}$ and $\mathrm{Co}_{1}, \mathrm{Co}_{2}, \mathrm{Co}_{3}, \mathrm{Co}_{4}, \mathrm{Co}_{5}, \mathrm{Co}_{6}$. In the same way, the second-order variable, "EXPERIENCE", is defined by some manifest variables linked to "DEVICES", "FRONT-OFFICE" and "PROCESS", in particular $\mathrm{Fr}_{1}, \mathrm{Fr}_{2}, \mathrm{Fr}_{3}, \mathrm{Fr}_{4}$ andPr $\mathrm{Pr}_{3}$ and $\operatorname{Pr}_{4}$.

The third-order variable, "OVERALL SATISFACTION", is defined by $\mathrm{Pr}_{3}, \mathrm{Pr}_{4}, \mathrm{Fr}_{2}, \mathrm{Fr}_{3}, \mathrm{Co}_{1}, \mathrm{Co}_{2}, \mathrm{Co}_{4}$, and Co5 and all variables that define "UTILITY".

We can conclude by saying that all indicators are good measures for their constructs, so there is discriminant validity in this scale.

The assumption of the specificity of the relation between latent variables and their manifest variable resulted is therefore confirmed. 


\subsection{Structural model}

In this section, we will present the results of PLS-PM, with an initial evaluation of statistical significance.

Reliable and valid outer model estimations permit an evaluation of the inner path model estimates. The essential criterion for this assessment is the coefficient of determination $\left(\mathrm{R}^{2}\right)$ of latent variables. Falk and Miller (1992) recommended the $\mathrm{R}^{2}$ for variable's variance explained by the independent variables. They also recommended the $\mathrm{R}^{2}$ be greater and equal to 0.10 . An $\mathrm{R}^{2}$ greater and equal to 0.10 ensures that the variance explained by the endogenous variables has practical, as well as statistical significance.

Table 5: Coefficients of determination $\left(\mathrm{R}^{2}\right)$

\begin{tabular}{cccccc}
\hline \hline & Original & Mean.Boot & Std.Error & Perc.025 & Perc.975 \\
\hline VALUE & 0.92 & 0.92 & 0.01 & 0.91 & 0.94 \\
EXPERIENCE & 0.94 & 0.94 & 0.00 & 0.93 & 0.95 \\
UTILITY & 0.79 & 0.79 & 0.02 & 0.76 & 0.83 \\
CO-CONSTRUCTION & 0.92 & 0.92 & 0.01 & 0.91 & 0.94 \\
DEVICES & 0.49 & 0.49 & 0.03 & 0.41 & 0.55 \\
FRONT-OFFICE & 0.81 & 0.81 & 0.01 & 0.78 & 0.84 \\
PROCESS & 0.88 & 0.88 & 0.01 & 0.86 & 0.90 \\
\hline \hline
\end{tabular}

The observed $\mathrm{R}^{2}$ value for the four first-order variables were found to be $0.92,0.94,0.79,0.92,0.49$, $0.81,0.88$ respectively (Table 5). Thus, the observed value is sufficiently higher than the recommended value (0.10).

The GoF index provides a measure of how thick the model is, using the geometric mean of total commonality and the overall $\mathrm{R}^{2}$. In the specific case, being 0.737 , it indicates a high overall model goodness.

In order to determine the confidence intervals of the path coefficients and statistical inference, bootstrap method was used (Tenenhaus et al., 2005). The path coefficients do not represent how much the highorder dimension affects the first-order sub-dimensions, but the extent to which the first-order constructs reflect the higher level of abstraction.

Table 6: Path Coefficients

\begin{tabular}{cccccc}
\hline \hline & Original & Mean.Boot & Std.Error & Perc.025 & Perc.975 \\
\hline OVERALL $\rightarrow$ VALUE & 0.96 & 0.96 & 0.00 & 0.95 & 0.97 \\
OVERALL $\rightarrow$ EXPERIENCE & 0.97 & 0.97 & 0.00 & 0.97 & 0.97 \\
VALUE $\rightarrow$ UTILITY & 0.89 & 0.89 & 0.01 & 0.87 & 0.91 \\
VALUE $\rightarrow$ CO-CONSTRUCTION & 0.96 & 0.96 & 0.00 & 0.96 & 0.97 \\
EXPERIENCE $\rightarrow$ DEVICES & 0.70 & 0.70 & 0.02 & 0.64 & 0.74 \\
EXPERIENCE $\rightarrow$ FRONT-OFFICE & 0.90 & 0.90 & 0.01 & 0.88 & 0.92 \\
EXPERIENCE $\rightarrow$ PROCESS & 0.94 & 0.94 & 0.01 & 0.93 & 0.95 \\
\hline \hline
\end{tabular}

The path coefficient results shown in the table clearly indicate that the original path coefficient values are equal scores with the path coefficient values obtained from bootstrap results (see Tables 5 and 6). This indicates that the path drawn in the model has a consistent relationship. However we can say the same thing for all first-order, second-order and third-order variables considered. 
Moreover, the confidence intervals shown in the table indicate clearly that the path coefficient values fall in this range. Thus, almost all the paths are significant in terms of the relationship between the firstorder and second-order variables.

The impact of all third-order and second-order variables is positive on all first-order variables, so all values are significant: we can say that the only third-order variable OVERALL SATISFACTION has a positive impact on the two second-order variables VALUE and EXPERIENCE (Table 6). "VALUE" has a positive impact on the first-order variables "UTILITY" and "CO-CONSTRUCTION"; "EXPERIENCE" variable has a positive impact of "DEVICES", "FRONT-OFFICE", "PROCESS".

The same can be said when analyzing the relationship between high-order variables and manifest variables: all values are significant (Table 7). From the path coefficient analysis, we can recognize overall statistical significance.

Table 7: Loadings of the Manifest Variables

\begin{tabular}{|c|c|c|c|c|c|}
\hline & Original & Mean.Boot & Std.Error & perc.025 & perc.975 \\
\hline OVERALL $\rightarrow \mathrm{Ut}_{1}$ & 0.810 & 0.809 & 0.014 & 0.781 & 0.833 \\
\hline OVERALL $\rightarrow \mathrm{Ut}_{2}$ & 0.804 & 0.803 & 0.016 & 0.771 & 0.831 \\
\hline OVERALL $\rightarrow \mathrm{Ut}_{3}$ & 0.829 & 0.829 & 0.013 & 0.803 & 0.855 \\
\hline OVERALL $\rightarrow \mathrm{Co}_{1}$ & 0.817 & 0.818 & 0.015 & 0.788 & 0.846 \\
\hline OVERALL $\rightarrow \mathrm{Co}_{2}$ & 0.805 & 0.806 & 0.018 & 0.772 & 0.837 \\
\hline OVERALL $\rightarrow \mathrm{Co}_{3}$ & 0.751 & 0.750 & 0.023 & 0.704 & 0.794 \\
\hline OVERALL $\rightarrow \mathrm{CO} 4$ & 0.819 & 0.818 & 0.013 & 0.792 & 0.845 \\
\hline OVERALL $\rightarrow \mathrm{Co}_{5}$ & 0.850 & 0.849 & 0.011 & 0.826 & 0.869 \\
\hline OVERALL $\rightarrow$ Co 6 & 0.796 & 0.795 & 0.015 & 0.762 & 0.824 \\
\hline OVERALL $\rightarrow \mathrm{De}_{1}$ & 0.574 & 0.575 & 0.032 & 0.511 & 0.636 \\
\hline OVERALL $\rightarrow \mathrm{De}_{2}$ & 0.587 & 0.589 & 0.027 & 0.538 & 0.640 \\
\hline OVERALL $\rightarrow \mathrm{De}_{3}$ & 0.531 & 0.532 & 0.032 & 0.463 & 0.593 \\
\hline OVERALL $\rightarrow \mathrm{Fr}_{1}$ & 0.782 & 0.781 & 0.017 & 0.746 & 0.811 \\
\hline OVERALL $\rightarrow \mathrm{Fr}_{2}$ & 0.823 & 0.822 & 0.014 & 0.791 & 0.846 \\
\hline OVERALL $\rightarrow \mathrm{Fr}_{3}$ & 0.819 & 0.819 & 0.014 & 0.790 & 0.844 \\
\hline OVERALL $\rightarrow \mathrm{Fr}_{4}$ & 0.793 & 0.793 & 0.015 & 0.763 & 0.818 \\
\hline OVERALL $\rightarrow \operatorname{Pr}_{1}$ & 0.752 & 0.752 & 0.020 & 0.717 & 0.788 \\
\hline OVERALL $\rightarrow \mathrm{Pr}_{2}$ & 0.705 & 0.707 & 0.022 & 0.667 & 0.750 \\
\hline OVERALL $\rightarrow \operatorname{Pr}_{3}$ & 0.814 & 0.813 & 0.016 & 0.779 & 0.845 \\
\hline OVERALL $\rightarrow \mathrm{Pr}_{4}$ & 0.808 & 0.808 & 0.015 & 0.779 & 0.836 \\
\hline$O_{V E R A L L} \rightarrow \operatorname{Pr}_{5}$ & 0.786 & 0.786 & 0.016 & 0.754 & 0.815 \\
\hline OVERALL $\rightarrow \operatorname{Pr}_{6}$ & 0.679 & 0.679 & 0.023 & 0.629 & 0.722 \\
\hline$V A L U E \rightarrow \mathrm{Ut}_{1}$ & 0.818 & 0.817 & 0.013 & 0.786 & 0.844 \\
\hline$V A L U E \rightarrow \mathrm{Ut}_{2}$ & 0.811 & 0.810 & 0.015 & 0.778 & 0.836 \\
\hline$V A L U E \rightarrow \mathrm{Ut}_{3}$ & 0.836 & 0.835 & 0.013 & 0.808 & 0.860 \\
\hline$V A L U E \rightarrow \mathrm{Co}_{1}$ & 0.853 & 0.854 & 0.012 & 0.828 & 0.876 \\
\hline VALUE $\rightarrow \mathrm{CO}_{2}$ & 0.857 & 0.858 & 0.014 & 0.833 & 0.885 \\
\hline$V A L U E \rightarrow \mathrm{Co}_{3}$ & 0.811 & 0.809 & 0.021 & 0.769 & 0.847 \\
\hline VALUE $\rightarrow \mathrm{Co}_{4}$ & 0.877 & 0.876 & 0.010 & 0.857 & 0.897 \\
\hline VALUE $\rightarrow \mathrm{Co} 5$ & 0.885 & 0.884 & 0.009 & 0.867 & 0.903 \\
\hline VALUE $\rightarrow \mathrm{Co}_{6}$ & 0.835 & 0.835 & 0.014 & 0.805 & 0.860 \\
\hline
\end{tabular}


Table 7: Loadings of the Manifest Variables (cont')

\begin{tabular}{|c|c|c|c|c|c|}
\hline & Original & Mean.Boot & Std.Error & perc.025 & perc.975 \\
\hline EXPERIENCE $\rightarrow \mathrm{De}_{1}$ & 0.621 & 0.621 & 0.030 & 0.564 & 0.679 \\
\hline EXPERIENCE $\rightarrow \mathrm{De}_{2}$ & 0.636 & 0.637 & 0.024 & 0.592 & 0.688 \\
\hline EXPERIENCE $\rightarrow \mathrm{De}_{3}$ & 0.572 & 0.572 & 0.031 & 0.507 & 0.631 \\
\hline EXPERIENCE $\rightarrow \mathrm{Fr}_{1}$ & 0.806 & 0.806 & 0.015 & 0.776 & 0.833 \\
\hline EXPERIENCE $\rightarrow \mathrm{Fr}_{2}$ & 0.844 & 0.844 & 0.012 & 0.820 & 0.865 \\
\hline EXPERIENCE $\rightarrow \mathrm{Fr}_{3}$ & 0.841 & 0.842 & 0.012 & 0.819 & 0.864 \\
\hline EXPERIENCE $\rightarrow \mathrm{Fr}_{4}$ & 0.802 & 0.803 & 0.014 & 0.778 & 0.829 \\
\hline EXPERIENCE $\rightarrow \mathrm{Pr}_{1}$ & 0.762 & 0.763 & 0.020 & 0.725 & 0.802 \\
\hline EXPERIENCE $\rightarrow \mathrm{Pr}_{2}$ & 0.748 & 0.749 & 0.018 & 0.714 & 0.786 \\
\hline EXPERIENCE $\rightarrow \operatorname{Pr}_{3}$ & 0.831 & 0.830 & 0.015 & 0.800 & 0.858 \\
\hline EXPERIENCE $\rightarrow \operatorname{Pr}_{4}$ & 0.809 & 0.808 & 0.015 & 0.778 & 0.836 \\
\hline EXPERIENCE $\rightarrow \operatorname{Pr} 5$ & 0.785 & 0.786 & 0.016 & 0.754 & 0.815 \\
\hline EXPERIENCE $\rightarrow \operatorname{Pr}_{6}$ & 0.701 & 0.701 & 0.022 & 0.657 & 0.740 \\
\hline UTILITY $\rightarrow \mathrm{Ut}_{1}$ & 0.904 & 0.904 & 0.008 & 0.886 & 0.921 \\
\hline UTILITY $\rightarrow \mathrm{Ut}_{2}$ & 0.934 & 0.934 & 0.007 & 0.919 & 0.947 \\
\hline UTILITY $\rightarrow \mathrm{Ut}_{3}$ & 0.927 & 0.927 & 0.006 & 0.914 & 0.938 \\
\hline $\mathrm{CO}-\mathrm{CONSTR} \rightarrow \mathrm{CO}_{2}$ & 0.868 & 0.868 & 0.013 & 0.844 & 0.891 \\
\hline $\mathrm{CO}-\mathrm{CONSTR} \rightarrow \mathrm{CO}_{3}$ & 0.867 & 0.866 & 0.016 & 0.835 & 0.896 \\
\hline $\mathrm{CO}-\mathrm{CONSTR} \rightarrow \mathrm{Co} 4$ & 0.917 & 0.916 & 0.007 & 0.901 & 0.929 \\
\hline $\mathrm{CO}-\mathrm{CONSTR} \rightarrow \mathrm{Co} 5$ & 0.912 & 0.911 & 0.008 & 0.895 & 0.925 \\
\hline $\mathrm{CO}-\mathrm{CONSTR} \rightarrow \mathrm{Co}_{6}$ & 0.875 & 0.875 & 0.011 & 0.852 & 0.894 \\
\hline DEVICES $\rightarrow \mathrm{De}_{1}$ & 0.897 & 0.897 & 0.011 & 0.875 & 0.917 \\
\hline DEVICES $\rightarrow \mathrm{De}_{2}$ & 0.913 & 0.913 & 0.008 & 0.898 & 0.926 \\
\hline DEVICES $\rightarrow \mathrm{De}_{3}$ & 0.805 & 0.804 & 0.021 & 0.761 & 0.841 \\
\hline FRONT-OFFICE $\rightarrow \mathrm{Fr}_{1}$ & 0.899 & 0.899 & 0.011 & 0.875 & 0.919 \\
\hline FRONT-OFFICE $\rightarrow \mathrm{Fr}_{2}$ & 0.940 & 0.940 & 0.005 & 0.928 & 0.950 \\
\hline FRONT-OFFICE $\rightarrow \mathrm{Fr}_{3}$ & 0.930 & 0.930 & 0.007 & 0.916 & 0.941 \\
\hline FRONT-OFFICE $\rightarrow \mathrm{Fr}_{4}$ & 0.886 & 0.886 & 0.010 & 0.867 & 0.904 \\
\hline PROCESS $\rightarrow \operatorname{Pr}_{1}$ & 0.789 & 0.789 & 0.017 & 0.751 & 0.822 \\
\hline PROCESS $\rightarrow \mathrm{Pr}_{2}$ & 0.812 & 0.813 & 0.015 & 0.787 & 0.844 \\
\hline PROCESS $\rightarrow \operatorname{Pr}_{3}$ & 0.884 & 0.884 & 0.011 & 0.864 & 0.904 \\
\hline PROCESS $\rightarrow \operatorname{Pr}_{4}$ & 0.869 & 0.869 & 0.011 & 0.846 & 0.889 \\
\hline PROCESS $\rightarrow \operatorname{Pr}_{5}$ & 0.842 & 0.842 & 0.013 & 0.817 & 0.865 \\
\hline PROCESS $\rightarrow \operatorname{Pr}_{6}$ & 0.754 & 0.753 & 0.018 & 0.711 & 0.792 \\
\hline
\end{tabular}

\subsection{Further analyses}

OVERALL SATISFACTION is not affected by gender (One-way ANOVA test: $\mathrm{F}[1 / 669]=0.351$; NS) or by age - Pearson $r[n=680]=0.079$ (ns with $\mathrm{p}<0.01$ ). However, it varies significantly over the 5 sectors (Oneway ANOVA test: $F[4 / 675]=49.332$, p $<0.000$; cf. Figure 4). Post-hoc comparisons shows that all differences among service sectors are significant. 
Figure 4: Levels of Overall Satisfaction* Service sectors

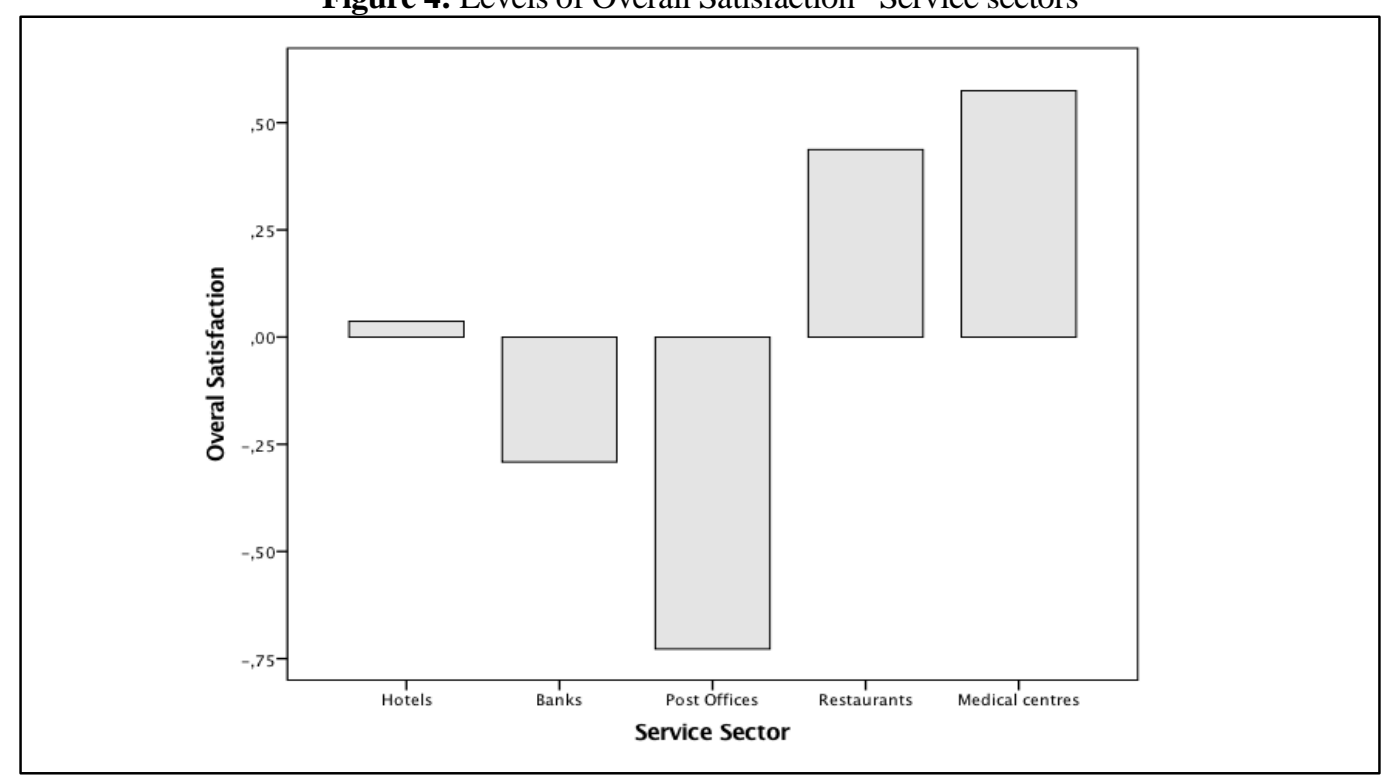

The correlation between the PROSERV OVERALL SATISFACTION and Global Satisfaction (as PCA of the 3 -item indicators) was very high and significant (Pearson $\mathrm{r}[\mathrm{n}=673]=0.886, \mathrm{p}>0.000$ ). The same can be said for the correlation between OVERALL SATISFACTION and the indicator of Loyalty (Pearson $\mathrm{r}[\mathrm{n}=672]=0.811, \mathrm{p}>0.000)$.

\section{DISCUSSION AND CONCLUSIONS}

The paper addressed the validation of the PROSERV model through a higher-ordered PLS-PM applied to a questionnaire (PROSERV-Q) based on it. In order to evaluate the theoretical model empirically, the validation was translated into 4 operative hypotheses: the PROSERV-Q questionnaire has a good level of reliability in terms of Alpha and Rho indexes, for each level of LVs (HP1); the PROSERV-Q underlies the three level dimensions modelled by PROSERV (first-order: UTILITY, CO-CONSTRUCTION; PROCESS, Front-office; DEVICES; Second-order: VALUE AND EXPERIENCE; third-order: Overall SATISFACTION) (HP2); the correlation between the estimated overall satisfaction with the external global satisfaction index (HP3) and Loyalty (HP4) shows the reproducibility of the global level of satisfaction and the effect of the model on the customer's loyalty.

In order to test these hypotheses, three steps of analysis were carried out on a sample of 680 users of services.

The first step of analysis was conducted to assess the quality of the questionnaire (HP1). Results showed that all the LVs have a high level of internal coherence and communality based on the Cronbach's alpha and Rho index. These two results, considered with the eigenvalues analysis bring us to the conclusion that the LVs defined are homogeneous and unidimensional. Moreover, the cross-loading shows the Manifest Variables are well distributed among the correspondent LVs, since the correlation is higher in blocks of reference. 
The second step of analysis was aimed at testing the validity of the PROSERV model. To this end, through the PLS-PM we analysed the underlying dimensions of the questionnaire, in order to check their consistency with the PROSERV model. The PLS-PM results support the validity of the PROSERV model (HP2). Indeed, the PM model proved to have a more than good global level of fit (GoF) - 0.737; moreover, each R-Square index resulted high and significant, based on the bootstrap results. Finally, the relationships between the different levels of abstractions, based on the path coefficients, are all positive, very high and significant, from the bootstrap point of view. Accordingly, one is led to conclude that the PROSERV model was confirmed by the way respondents organized their responses to the questionnaire.

The third step of analysis concerns the Overall satisfaction estimated by the PLS-PM model. Consistently with the Hypothesis 3 and Hypothesis 4, the Overall satisfaction was associated very strongly with a direct measure of the level of global satisfaction and an independent indicator of Loyalty, respectively. These analyses provide complementary evidence in support of the validity of the PROSERV model and PROSERV-Q. Indeed, they show that the parameter calculated from PROSERV$\mathrm{Q}$, on the grounds of the PROSERV model corresponds very closely to how clients respond when asked directly about their global satisfaction with the service as well as about their intention to keep on using it. There is reason to conclude that this is so because the three-level PROSERV model is able to capture the fundamental constitutive components of customer satisfaction that work as the source of the client's overall attitude towards the service, both in terms of its global evaluation and of loyalty.

Finally, it is worth highlighting that the results of this study, by supporting the PROSERV model, are a contribution to the development of the concept of service value in relational terms, namely in the direction of recognising the centrality of the tenet of prosumership, taking the client-provider exchange as the place and the process through which the value is construed.

Needless to say, this study was affected by limitations that limited it generalizability. First, it must be admitted that the use of a convenience sample reduces its representativeness. Second, the analyses were based on respondents recruited within a restricted population - both in geographic terms and service sectors. Finally, analyses were carried out on the whole sample, without considering the specificity of the service sectors. This is consistent with the idea that the PROSERV is a global model, being transversal to the content of the service. Yet the current study adopted such a view as a taken-for-granted assumption, rather than a hypothesis to test.

Thus, we consider the findings reported in this paper as a promising first step in the direction of developing a new approach to the conceptualization and measurement of customer satisfaction. Further studies will tell to what extent the current evidence of PROSERV validity can be generalized to other cultural and linguistic contexts as well as service sectors.

\section{REFERENCES}

Anderson, E. W., \& Fornell, C. (2000). Foundations of the American customer satisfaction index. Total quality management, 11(7), 869-882.

Andreassen T. W., \& Lindestad, B. (1998). Customer loyalty and complex services: The impact of corporate image on quality, customer satisfaction and loyalty for customers with varying degrees of service expertise. International Journal of service Industry management, 9(1), 7-23. 
Bayol, M. P., de la Foye, A., Tellier, C., \& Tenenhaus, M. (2000). Use of PLS path modeling to estimate the European consumer satisfaction index (ECSI) model. Statistica Applicata, 12(3), 361-375.

Blalock, H. M. (1960). Social statistics (Vol. 2). New York: McGraw-Hill.

Ciavolino, E., \& Nitti, M. (2013). Simulation study for PLS path modelling with high-order construct: A job satisfaction model evidence. In A. N. Proto, M. Squillante \& J. Kacprzyk (Eds.), Advanced Dynamic Modeling of Economic and Social Systems (pp. 185-207). Heidelberg, Berlin: Springer.

Cronin Jr, J. J., \& Taylor, S. A. (1994). SERVPERF versus SERVQUAL: reconciling performancebased and perceptions-minus-expectations measurement of service quality. The Journal of Marketing, 58(1), 125-131.

Deming, W. E. (1986). Out of the Crisis. Cambridge: Massachusetts Institute of Technology, Center for Advanced Engineering Study.

ECSI Technical Committee. (1998). European Customer Satisfaction Index: Foundation and Structure for Harmonised National Pilot Projects. ECSI Steering Committee.

Falk, R. F., \& Miller, N. B. (1992). A primer for soft modeling. Akron, Ohio: The University of Akron.

Fornell, C. (1992). A national customer satisfaction barometer: The Swedish experience. The Journal of Marketing, 56(1), 6-21.

Gronholdt, L., Martensen, A., \& Kristensen, K. (2000). The relationship between customer satisfaction and loyalty: cross-industry differences. Total quality management, 11(4-6), 509-514.

Grönroos C. (2000). Service Management and Marketing ( $2^{\text {nd }}$ edition). Chichester: John Wiley \& Sons.

Kristensen, K., Martensen, A., \& Gronholdt, L. (2000). Customer satisfaction measurement at post Denmark: results of application of the European customer satisfaction index methodology. Total Quality Management, 11(7), 1007-1015.

Ladhari, R. (2009). A review of twenty years of SERVQUAL research. International Journal of Quality and Service Sciences, 1(2), 172-198. doi: 10.1108/1756669091097144.

Lohmöller, J.-B. (1989). Latent variable path modeling with partial least squares. Heidelberg: Physica.

Matzler, K., Hinterhuber, H. H., Bailom, F., \& Sauerwein, E. (1996). How to delight your customers. Journal of Product \& Brand Management, 5(2), 6-18.

Mehra S., \& Ranganathan S. (2008). Implementing total quality management with a focus on enhancing customer satisfaction, International Journal of Quality \& Reliability Management, 25(9), 913927. doi: 10.1108/02656710810908070.

Mossi, P., \& Salvatore, S. (2012). La soddisfazione dell'utenza scolastica. Come rilevarla e come interpretarla. Milano: Franco Angeli.

Neave, H. R. (1987). Deming's 14 points for management: framework for success. The Statistician, $36(5), 561-570$.

Nitti, M., \& Ciavolino, E. (2014). A deflated indicators approach for estimating second-order reflective models through PLS-PM: An empirical illustration. Journal of Applied Statistics, 41(10), 22222239.

Norman, R. (1986). Service management: Strategy and leadership in service businesses. England: John Wiley and Sons Ltd.

Oliver, R. L. (2010). Satisfaction: A behavioral perspective on the consumer. New York: . ME Sharpe. Inc.

Parasuraman, A., Zeithaml, V. A., \& Berry, L. L. (1985). A conceptual model of servicequality and its implications for future research. Journal of Marketing, 49(4), 41-50.

Parasuraman, A., Zeithaml, V. A., \& Berry, L. L. (1988). SERVQUAL: a multi-item scale for measuring consumer perceptions of the service quality. Journal of Retailing, 64(1), 12-40.

Rocco, D., Gennaro, A., Salvatore, S., Stoycheva V., Bucci W. (2017). Clinical Mutual Attunement and the Development of Therapeutic Process: A Preliminary Study. Journal of Constructivist Psychology, 30(4), 371-387. 
Safran, J. D., \& Muran, J. C. (2000). Negotiating the therapeutic alliance: A relational treatment guide. New York, US: Guilford Press.

Salvatore S. (2016). Psychology in black and white. The project of a theory-driven science. Charlotte, NC: Information Age Publishing.

Salvatore S., \& Scotto di Carlo, M. (2005). L’intervento psicologico per la scuola. Modelli, metodi, strumenti. Roma: Edizioni Carlo Amore - Firera Publishing Group.

Salvatore S., Gennaro A., Calogiuri S., \& Manfreda A. (2017), Logics of Value Construction. For a semio-dialectical approach to organization and social action. Forthcoming.

Salvatore S., Ligorio. M. B., \& De Franchis, C. (2005). Does Psychoanalytic Theory Have Anything to Say on Learning? European Journal of School Psychology, 3(1), 101-126.

Salvatore, S., \& Gennaro, A. (2012). The inherent dialogicality of the clinical exchange. International Journal for Dialogical Science, 6(1), 1-14.

Salvatore, S., \& Venuleo, C. (2017). Liminal transitions in a semiotic key: The mutual in-feeding between present and past. Theory \& Psychology, 27(2), 215-230.

Tanzilli, A., Colli, A., Del Corno, F., \& Lingiardi, V. (2016). Factor structure, reliability, and validity of the Therapist Response Questionnaire. Personality Disorders: Theory, Research, and Treatment, 7(2), 147-158.

Tenenhaus, M., Vinzi, V. E., Chatelin, Y. M., \& Lauro, C. (2005). PLS path modeling. Computational statistics \& data analysis, 48(1), 159-205.

Venuleo, C., Mossi P., \& Salvatore, S. (2016). Educational subcultures and dropping out in higher education. A longitudinal case study. Studies in Higher Education, 41(2), 321-342. 10.1080/03075079.2014.927847.

Zeithaml, V. A., \& Bitner M.-J. (2003). Services Marketing - Integrating Customer Focus Across the Firm. Boston, MA: McGraw-Hill. 